\title{
THE ROLE OF NUCLEAR DIPLOMACY
}

\author{
Samodra Sriwidjaja \\ Former Ambassador Indonesia for Austria
}

\begin{abstract}
THE ROLE OF NUCLEAR DIPLOMACY. In the midst of nuclear countries and non-nuclear countries in the framework of non-proliferation and disarmament, Indonesia has played an important role. Indonesia has been actively involved in each activity at the international level to create a world free from nuclear weapons. This involvements needs to be maintained and increased in the years to come. As a large country, Indonesia should play a key role in the field of nuclear diplomacy. All of the efforts of nuclear diplomacy as mentioned above had a clear objective to support Indonesia's energy program, at the institution framework as well as capacity building. Indonesia's effort is also directed to attain appropriated international public acceptance.
\end{abstract}

Keywords : Nuclear diplomacy, Non-Proliferation Treaty, CTBT, NPP

\section{INTRODUCTION}

Let me start by expressing my appreciation to the committee for giving me an opportunity to speak before Women in Nuclear. It is indeed my first experience during almost 40 years my carrier as Indonesian Diplomat to attend The International Conference and the majority of the participants are women. Not ordinary women but women in nuclear. I can't imagine if the women going to strike, certainly, there will be no more nuclear program. Ladies and gentlemen why do we chose the role of Nuclear Diplomacy? Before continuing this deliberation, permit me to know briefly the essence of Diplomacy and Terminology surrounding it. Diplomacy is means to gain national interest by peaceful means. Diplomat is the man who carrying out diplomacy. Diploma is certificate for person who has already trained by diplomatic skill and experience. Diplomatic is the end result of diplomacy. Because atomic energy is beneficial for human being so the best approach in gaining nuclear for peaceful and prosperity used is through diplomacy. As you would be aware, that immediately after the tragic bombing in Hiroshima and Nagasaki, August 45, leaders and experts either in Europe or USA realized the danger of Atomic Energy.

Soon after being inaugurated as the President of the United States of America, Dwight D. Eisenhower realized that the rapid development of nuclear weapons after World War II leads to the destruction of the world. In efforts to persuade the American society (people) to accept measures to control arms race, Eisenhower felt the need to elaborate on the implausible force of nuclear weapons. In his speech entitled „Atom for Peace" in front of the General Assembly of the United Nations on 8 December 1945, apart from forewarning on the dangers of nuclear, Eisenhower also presented his 
thoughts on transforming atomic energy for the benefit of the welfare of the human race.

Today, 62 years after Eisenhower's historical speech. However, the international effort to disarm nuclear weapons, as well as non-proliferation, is still pursued intensively without certainty to a successful comprehensive conclusion and to the satisfaction of all parties concerned. In this regard, the Non-Proliferation Treaty (NPT), a treaty that is internationally recognized as a binding agreement on weapons control adhered to by almost every country in the world, is still being reviewed periodically on its effectiveness.

\section{NPT (Treaty on the Non-Proliferation of Nuclear Weapons)}

The Treaty was opened for signature on 1 July 1968, and was signed by the United States, United Kingdom, and former Soviet Union and 59 other countries. The treaty entered into force with the deposition of the instrument of ratification of the United States on 5 March 1970. Today, after 37 years the NPT entered into force, excluding India and Pakistan, as well as North Korea who withdrew in early 2003, 190 countries have become parties to the Treaty[1].

In general, it is worth mentioning that the NPT is relatively a short Treaty with only 11 articles. From these 11 articles, there 3 main articles that have been debated on its implementation, which article I related to disarmament, article II on non-proliferation, and article IV on the inalienable right of State Parties to develop its nuclear energy for peaceful purposes without discrimination.

In line with article $\mathrm{X}$ of the NPT, 25 year later after its entry into force, there is a need to hold a Conference to decide whether the Treaty should continue without any time limits, or extended for a certain period. For that very reason, on 11 May 1995 a NPT Review Conference was held in New York. At this review 3 decisions and a resolution were adopted. The first decision was to extend the NPT without any time limit and without any preconditions. The second decision was that the principle and objectives of non-proliferation and disarmament was formulated to assist State Parties in implementing the next phase. The third decision was the enhancement of the process of review for the preparation of review conference in the future. The resolution that was adopted was the establishment of a nuclear weapons free zone in the Middle East.

At the Review Conference in 2000, a phenomenal decision was taken which agreed on 13 practical steps as a systematic and progressive effort to attain total disarmament. The 13 practical steps are as follows [2] :

1. The signing of the Comprehensive Nuclear-Test-Ban Treaty (CTBT):

The importance of all States in the world to sign and ratify the CTBT as 
soon as possible, without any condition in line with its the constitutional process, with the purpose of expediting entry into force.

2. Test Ban: The moratorium of nuclear test and detonation albeit the CTBT has not entered into force.

3. Negotiation: The need to negotiate at the Conference on Disarmament for the prohibition to produce nuclear fissile materials for nuclear weapons and for its other nuclear detonating equipments.

4. Negotiation: The need to establish a subsidiary body at the Conference on Disarmament with the mandate to handle disarmament.

5. Irreversibility: The irreversibility principle applies for the nuclear disarmament.

6. Elimination of Nuclear Weapons: The commitment of nuclear States for the total elimination of its nuclear weapons in respect of disarmament in accordance with article VI of the NPT.

7. Enforcement of existing treaties: The full implementation of START II and the conclusion of START III in order to strengthen the ABM Treaty as the first stepping stone for a strategic stabilizer and as the basis for further reduction of the strategic offensive weapons.

8. Implementation of existing treaties: The conclusion and implementation of the three party initiatives of the US, Russian Federation, and IAEA, which contains verification of fissile materials from weapons and other materials which has been eliminated from their defense programs.

9. Step by step: The gradual implementation of all nuclear weapon states to eliminate their nuclear weapons to promote international stability.

10. Fissile material under IAEA's surveillance: The agreement from nuclear weapon countries to place disposed fissile materials for military purpose under IAEA's surveillance.

11. Disarmament in general and in full: The reaffirmation to the ultimate aim for the general and in full disarmament under the effective international control.

12. Reporting: Periodical report of all State Parties on the implementation of article VI of the NPT.

13. Verification: Verification capacity needed to guarantee compliance to the disarmament agreement to achieve and maintain a world free from nuclear weapons.

The previous Review Conference was held from 2 - 27 May 2005. 150 State Parties, 13 regional/international organizations, and 119 research institutions and non-governmental organization in the field of nonproliferation and disarmament attended the Conference. However many observed that this was the worst conference ever which resulted in many procedural reports, and substantive recommendation did not achieve an agreement. From the three main committees that were given the mandate to conduct substantive discussion, only the First Committee on Non- 
Proliferation and Disarmament succeeded in submitting their report attached with the working paper to the Conference, however the text of the working paper did not achieve consensus. The Second Committee on Nuclear Weapons Free Zone, Safeguard and Regional Issues and the Third Committee on the Use of Nuclear Energy for Peaceful Purposes, Universality and Withdrawal did not succeed to attach their substantive document in their reports[3].

\section{NPT AND IAEA}

Though not a Party to the NPT, the International Atomic Energy Agency, is entrusted and plays a key role, as well as is responsible in implementing the NPT. Based on article III of the NPT the IAEA implements international safeguards to verify non-nuclear countries that are State Parties to the NPT fulfill their non-proliferation commitments with the objective of preventing diversion of nuclear energy for peaceful purpose into nuclear weapons or other detonating equipments. Meanwhile article IV of the NPT stipulates that IAEA facilitates and provide opportunities to further develop the application of nuclear energy for peaceful purposes, in particular to non-nuclear State Parties with utmost consideration of the needs of developing countries.

In order to implement article III of the NPT, the IAEA enters into agreement on the comprehensive safeguards agreement with non-nuclear State Parties of the NPT. Till the mid of 2005140 countries have placed their materials and nuclear activities under the safeguards agreement with the IAEA. However, there are still 36 State Parties which have not concluded their comprehensive safeguards agreement, with 13 countries which have signed the agreement but have not ratified it, 3 have been agreed by the Board of Governors of the IAEA but have not signed it, and 20 countries have not submitted their comprehensive safeguards agreed to the Board of Governors of the IAEA for its consideration.

In order to strengthen the comprehensive safeguards agreement, the IAEA further devised an additional protocol, which would allow IAEA to inspect locations or other installations, apart from nuclear facilities to verify non-proliferation commitments. Till now, 113 countries have been agreed by the Board of Governors to implement the additional protocol, 104 countries have signed it and 69 countries have concluded in full.

As a country with a strong commitment in non-proliferation and disarmament, Indonesia has concluded the comprehensive safeguards agreement and the additional protocol since 1999. Furthermore, Indonesia is one of the three countries (the other two countries are Australia and Norway) which has concluded the integrated safeguards, a more flexible approach in implementing safeguards in focusing verification with limited resources, 
including areas in which the inspectors needs to concentrate on, locations that they should observe and tools that are needed to verify.

Prior to the $50^{\text {th }}$ Anniversary of the IAEA, which will be held in July 2007, the IAEA Secretariat proposed main activities as follows:

- Special Scientific Forum at the $50^{\text {th }}$ General Conference on the new framework for nuclear fuel cycle.

- A series of holding special forums all year long in various regions on nuclear application and technical cooperation, nuclear energy, nuclear security and safety, and safeguards.

- Adoption of a commemorative declaration of all member countries of the IAEA at the $50^{\text {th }}$ General Conference, record of IAEA's achievements in the past and designing the targets for the future.

The Secretariat requested Member Countries to support IAEA's activities for the anniversary, including sending high-level dignitaries to the $50^{\text {th }}$ General Conference, and submit memorabilia for the exhibition.

The following activities needs to brought to the attention of the Indonesian Government to utilize the momentum of the $50^{\text {th }}$ Anniversary of IAEA, as follows:

a. Cooperate with the IAEA to conduct activities to increase people's awareness on the benefits of nuclear energy, including holding a seminar or a workshop in Jakarta. These activities can also be utilized to prepare and socialize the plan to develop and operate a nuclear power plant by 2017 .

b. In regards to the exhibition, Indonesia can contribute artifacts or arts, such as statues or paintings as a commemorating the Anniversary.

c. Sending the highest level of dignitaries to the $50^{\text {th }}$ General Conference of the IAEA in September 2007.

d. Signing or ratifying international instruments related to nuclear, in particular the Joint Convention on the safety of Spent Fuel Management and an the Safety of Radioactive Waste Management.

e. Publish at the national level and/or the United Nations on the success story of Indonesia's cooperation with IAEA and future challenges.

\section{CTBT}

One of the international instruments in monitoring nuclear test and detonation is the CTBT (Comprehensive Nuclear-Test-Ban-Treaty). This is one of the complex treaties ever formulated and took many years, since its first proposed in 1950 until its adoption in 1996.

However, until now the CTBT has not entered into force. Albeit almost all countries of the world recognize the noble objectives of the treaty, in 
reality international power plays an important role in which many country awaits the response from the Unites States. President Bill Clinton was the first world leader who signed the treaty, and had reminded the Congress that if the US failed to ratify the CTBT, this would bring a signal to the world that the US is against non-proliferation. However Congress opposed to ratify in October 1999 after the Republicans stated that the CTBT would fail to monitor States.

In general, the treaty consisted of a preamble, 17 articles, 2 annexes and one protocol with 2 annexes. Annex 1 provides a list of countries based on geographical regional representation for the election of the Executive Board, and annex 2 provides the list of 44 states that needs to ratify the convention in order to enter into force. The protocol consisted of 3 parts, the first part elaborated the functions of International Monitoring System (IMS) and the International Data Centre (IDC), part two established the procedure for on-site inspections, and part three is related to confidence building measures. Annex 1 of the protocol provides a list of facilities that are a part of the IMS network, and annex 2 provides a list of characteristic parameters to verify the standard of events of data being processed through the IDC.

Based on article XIV, the treaty will enter into force after 180 days, after 44 states listed in annex 2 have ratified. The 44 countries are states that have a nuclear power plant or a nuclear research reactor, which in theory has the capacity to produce materials for a nuclear bomb. From the 44 countries, 41 countries have signed, and 22 countries have ratified. However North Korea, India and Pakistan included in the list have not signed the treaty. Indonesia is among the 44 countries listed in annex 2, has signed the treaty in 1996, however due to eventful domestic works to complete its reformation and democratization process, the ratification of the CTBT is not of priority. As known, that in July 2002, President Megawati Soekarnotputri had iterated the Governments position that nuclear technology will be used for peaceful purposes and instructed the Minister for Foreign Affairs to arrange the ratification of the CTBT.

Though the treaty has not entered into force, in the framework of the UN the Provisional Technical Secretariat of the Preparatory Commission of the CTBT Organization (CTBTO) had been established. Till now, CTBTO is still preparing and strengthening its technical capacities in detecting explosion from nuclear tests. In the framework of IMS and IDC, CTBTO has 321 monitoring stations and 16 laboratories. CTBTO's technical capacities can be benefited for science and civil use apart from its main task.

\section{CHALLENGES FACED BY THE WORLD TODAY}

Albeit all that, international instruments in efforts for non-proliferation and disarmament is readily available, however in reality the hope for a world without nuclear weapons is still a dream. As portrayed in the holding of the 
Review Conference of the NPT in May 2005 in New York, all countries agreed that non-proliferation and disarmament is faced with a complicated challenge in its integrity and effectiveness. However, they differ from characterizing the main threat and the needs to respond to the challenge.

The challenges that the world is facing in regards to non-proliferation and disarmament among others are as follows:

1. The withdrawal of North Korea from the NPT. To many of the Western countries the withdrawal is considered as the efforts of the North Koreans in developing its nuclear weapons. However, North Korea firmly stated that they have withdrew from the NPT because of their distrust towards the US that the US is taking advantage of the IAEA to spy on their domestic problems and curb the socialist system in North Korea. In this regard we have to observe the latest development concerning the progress of the countries in facilitating the negotiation with North Korea.

2. Efforts of countries in implementing nuclear fuel cycle, which theoretically can be utilized to develop nuclear weapons. Some countries are of the view the ability for nuclear fuel cycle should be limited to each country, and some countries are of the view that the limitation is applicable to certain suspected countries only.

3. The findings of nuclear programmes that have not been reported to the IAEA in the framework of the safeguards agreement, such as in Libya, South Korea, Egypt and Iran. The black market that was established by Dr. A.Q. also indicated the weakness in the safeguards system of the IAEA.

4. There are some reservations of certain countries to implement their commitments of agreed upon at the Review Conference of the NPT in 2000. This is the reason for Egypt's refusal of the provisional agenda of the Conference, which have been formulated by the President of the Conference that did not reflect the commitment in 2000.

5. A fact that Israel refuses to join the NPT. In a broader context, this country is a part of the "three country problem" together with India and Pakistan, who also refuses to join the NPT. However, the latest development is the agreement on nuclear cooperation between the US and India, in which the later is seriously considering joining the NPT.

6. Finally, the escalating threat of terrorism has raised awareness on the safety and security of nuclear weapons, fissile materials, technology, and nuclear facilities. Bearing these facts in mind, there is a need to increase measures to reduce and eradicate terrorist threat.

\section{THE ROLE OF INDONESIA'S DIPLOMACY}

In a world of uncertainty on matters related to non-proliferation and disarmament, Indonesia plays a significant role in efforts to curb those 
uncertainties. In the framework of the Non-Aligned Movement, the Indonesian Permanent Mission in New York has been coordinator for disarmament in past years. In the history of Indonesia's diplomacy it is noted that President Soekarno at $15^{\text {th }}$ General Assembly on 30 September 1960 submitted a draft resolution on disarmament.

Furthermore, the Indonesian Permanent Mission in Vienna, in which the Secretariat of IAEA is located, have been involved actively in various meetings of the Board of Governors of IAEA that discusses issues on safeguards and verification. After 40 years without having taken an important seat, on September 2002, Indonesia succeeded in becoming the President of the General Conference of the IAEA at its $46^{\text {th }}$ session. The Permanent Representative of the Republic of Indonesia during January to June 2005 had also taken the Chairmanship of the G-77 and China, which is tasked to prepare group statements on matters relating to the meetings of the Board of Governors of the IAEA relating to the groups position on matters relating with safeguards and verification. Apart from being the Vice Chair of the CTBT, Indonesia's role in the Board of Governor of the IAEA will become more important in 2005-2007 [4-7].

In this regard, during the NPT Review Conference, Ambassador Sudjadnan Parnohadiningrat, Secretary General of the Ministry of Foreign Affairs had the opportunity to Chair the First Committee as have been elaborated above. This Committee was the only committee that succeeded in submitting the substantive working paper, although it was not adopted by consensus.

The above accomplishment was supported by nuclear and non-nuclear countries to the Chair of the First Committee in bridging principle differences between State Parties to formulate a balanced, comprehensive and impartial working paper. The success of this effort was not only the appreciation of the international community towards Indonesia's leadership in multilateral diplomacy, particularly in the field of non-proliferation and disarmament, but also as a proof of international recognition towards Indonesia's role in efforts to secure and maintain international peace and security as mandated in the 1945 Constitution and the Charter of the United Nations.

Recent events, such as Indonesia non-permanent membership in the Security Council is reflection of Indonesia's role in maintaining peace and international security. One of the roles is the effort of Indonesia to advocate the peaceful use of nuclear and the inalienable right of States to attain nuclear technology for peaceful purposes. The Security Council's resolution $1747-$ is a test case for Indonesia's role in the Security Council. Indonesia had voted for the resolution, albeit strong resentments back home. However, the decision to vote for should not be taken as "face-value" - the process of negotiating the draft resolution should be highlighted, as all diplomacy runs in parallel to negotiations and compromising. Three proposals for amendments to the resolution should be borne in mind. First the proposal to 
reaffirm the inalienable rights of countries to attain nuclear technology for peaceful purposes, secondly the need for free nuclear weapons free zone in the middle, and thirdly the need to further negotiations and diplomacy in pursuing a common resolve on the Iranian nuclear issues. This showcases Indonesia's main principles of foreign policy towards non-proliferation and disarmament. This three proposals that was adopted, portrays Indonesia to be balanced and impartial in observing the issue related with Iran's nuclear programme. It also does not undermine, that in many aspect Indonesia is supporting Iran.

\section{CONCLUSION}

Non-proliferation and disarmament cannot be denied that it is the biggest challenge of the world to create a safe and peaceful world free from nuclear weapons. Enhanced efforts of countries needs to be furthered to attain those noble goals. A variety of international instruments in a form of treaties, conventions and agreements have been successfully formulated and entered into force and binding to State Parties. However it is not enough. Trust, honesty and sincerity of all parties are still uncommon in the activities of multilateral diplomacy in the field of non-proliferation and nuclear disarmament.

In the midst of nuclear countries and non-nuclear countries in the framework of non-proliferation and disarmament, Indonesia has played an important role. Indonesia has been actively involved in each activity at the international level to create a world free from nuclear weapons. This involvements needs to be maintained and increased in the years to come. As a large country, Indonesia should play a key role in the field of nuclear diplomacy.

All of the efforts of nuclear diplomacy as mentioned above had a clear objective to support Indonesia's energy programme, at the institution framework as well as capacity building. Indonesia's effort is also directed to attain appropriated international public acceptance.

\section{REFERENCES}

1. IAEA, Resolutions and Other Decisions of The General Conference (2001-2005).

2. IAEA, Meetings of the Board of Governors (2002-2005).

3. NPT Review Conference, New York (2005).

4. Status of the Preparation of the Development of Nuclear Power Plants in Indonesia, Work Meeting of BATAN (April 2006). 
5. BATAN, Nuclear Energy as a Part of the National Energy System LongTerm Period, Executive Summary (2005).

6. Formulations and Recommendations from the Result of KATN (November 2006).

7. The Role of Nuclear Electric Power Plant and Public Acceptance (February 22, 2007). 